\title{
Massed Training-Induced Intermediate-Term Operant Memory in Aplysia Requires Protein Synthesis and Multiple Persistent Kinase Cascades
}

\author{
Maximilian Michel, Charity L. Green, Jacob S. Gardner, Chelsea L. Organ, and Lisa C. Lyons \\ Department of Biological Science, Program in Neuroscience, Florida State University, Tallahassee, Florida 32306-4295
}

The Aplysia feeding system with its high degree of plasticity and well characterized neuronal circuitry is well suited for investigations of memory formation. We used an operant paradigm, learning that food is inedible (LFI), to investigate the signaling pathways underlying intermediate-term memory (ITM) in Aplysia. During a single massed training session, the animal associates a specific seaweed with the failure to swallow, generating short-term $(30 \mathrm{~min})$ and long-term $(24 \mathrm{~h})$ memory. We investigated whether the same training protocol induced the formation of ITM. We found that massed LFI training resulted in temporally distinct protein synthesis-dependent memory evident $4-6 \mathrm{~h}$ after training. Through in vivo experiments, we determined that the formation of ITM required protein kinase A, protein kinase $\mathrm{C}$, and MAPK. Moreover, the maintenance of ITM required PKA, PKM Apl III, and MAPK because inhibition of any of these kinases after training or before testing blocked the expression of memory. In contrast, additional experiments determined that the maintenance of long-term memory appeared independent of PKM Apl III. Using Western blotting, we found that sustained MAPK phosphorylation was dependent upon protein synthesis, but not PKA or PKC activity. Thus, massed training-induced intermediate-term operant memory requires protein synthesis as well as persistent or sustained kinase signaling for PKA, PKC, and MAPK. While short-, intermediate-, and long-term memory are induced by the same training protocol, considerable differences exist in both the combination and timing of signaling cascades that induce the formation and maintenance of these temporally distinct memories.

\section{Introduction}

Temporally discrete memory forms exist with short-term memory (STM) lasting minutes, intermediate-term memory (ITM) lasting hours, and long-term memory (LTM) lasting days (Bailey et al., 2008). Although relatively recently identified, ITM has been observed for many paradigms, including sensitization and dishabituation in Aplysia (Sutton and Carew, 2000; Sutton et al., 2001; Li et al., 2005; Antonov et al., 2010), one-trial conditioning in Hermissenda (Crow et al., 1999); olfactory conditioning in insects (Schwärzel and Müller, 2006; Berry et al., 2008), avoidance learning in chick (Gibbs and Ng, 1976; Patterson et al., 1986; Johnston et al., 1998), operant conditioning in Lymnaea (Lukowiak et al., 2000), and novel object recognition in mice (Taglialatela et al., 2009). Studies in Aplysia and Lymnaea have significantly furthered insights into the mechanisms underlying ITM. However, much of the information has been generated using different protocols for the induction of STM, ITM, and LTM. The use of a single paradigm that induces multiple forms of memory would provide direct comparisons regarding the time frames and com-

Received Dec. 16, 2011; revised Jan. 27, 2012; accepted Feb. 12, 2012.

Author contributions: M.M. and L.C.L. designed research; M.M., C.L.G., J.S.G., C.L.O., and L.C.L. performed research; M.M. and L.C.L. analyzed data; M.M. and L.C.L. wrote the paper.

This research was supported by National Institute of Mental Health Grant R01MH81012 to L.C.L. We thank Gordon Averill for his assistance with preliminary behavioral studies.

Correspondence should be addressed to Dr. Lisa C. Lyons, Department of Biological Science, Florida State University, 319 Stadium Drive, Tallahassee, FL 32306-4295. E-mail: lyons@bio.fsu.edu.

DOI:10.1523/JNEUROSCI.6264-11.2012

Copyright $\odot 2012$ the authors $\quad 0270-6474 / 12 / 324581-11 \$ 15.00 / 0$ binations of signaling pathways required for temporally separated memories. We investigated ITM in Aplysia californica using the learning that food is inedible (LFI) operant paradigm, a massed training paradigm that induces robust STM and LTM.

Feeding behavior in Aplysia encompasses a high degree of neural plasticity (Elliott and Susswein, 2002; Cropper et al., 2004) with complex learning paradigms established (Baxter and Byrne, 2006). With LFI training, the animal associates repeated failed swallowing attempts with a specific seaweed (Susswein et al., 1986; Michel et al., 2011a). During the induction of memory, nitric oxide and histamine signal failed swallowing (Katzoff et al., 2002, 2010). For LTM, LFI requires activation of MAPK, PKA, $\mathrm{PKC}$, and PKG signaling cascades, poly-ADP ribosylation and the induction of the immediate early gene ApC/EBP (CCAAT enhancer binding protein; Cohen-Armon et al., 2004; Levitan et al., 2008; Michel et al., 2011a,b). In contrast, STM requires neither PKA nor PKC signaling, but depends upon MAPK (Michel et al., 2011a,b). Intermediate LFI memory has only been observed using a spaced training protocol with little known regarding the molecular requirements of ITM apart from nitric oxide (Botzer et al., 1998; Katzoff et al., 2002).

Using a single massed LFI training session, we identified ITM dependent upon translation but not transcription. We investigated the requirements for kinase signaling for ITM in vivo. We found that PKA, PKC, and MAPK were all necessary for ITM from induction through maintenance of memory. Prolonged MAPK activation was dependent upon protein synthesis, but not PKA or PKC. The use of the same training paradigm for STM, 
ITM, and LTM allows direct comparisons of the mechanisms for induction and maintenance of each type of memory. Our results demonstrated significant differences in the kinase cascades required for STM and ITM and striking temporal differences for kinase activity between ITM and LTM. Thus, considerable complexity and variation exists in the mechanisms underlying different forms of memory even generated by the same protocol.

\section{Materials and Methods}

Animal maintenance. Hermaphroditic Aplysia weighing 100-200 g (Santa Barbara Marine, Alacrity, Marinus Scientific) were housed in individual boxes in 100 gallon circulating seawater (ASW; Instant Ocean, Aquarium Systems) tanks at $15^{\circ} \mathrm{C}$ on $12 \mathrm{~h}$ light/dark cycles. Animals were fed romaine lettuce three times a week. Five days before behavioral experiments, animals were fed to satiation on laver seaweed and subsequently removed from appetitive stimuli. Animals received LFI training as originally established by A. Susswein (Susswein et al., 1986; Botzer et al., 1998; Katzoff et al., 2002) with previous modifications (Michel et al., $2011 \mathrm{a}, \mathrm{b})$. Briefly, animals in individual bowls were presented with netted laver seaweed $(\sim 3.5 \mathrm{~mm} \times 3.5 \mathrm{~mm})$ to which the animals responded with head-waving, biting, and attempts to swallow the seaweed. Fulllength training continued until 3 min elapsed without the animal's taking the seaweed bag into the mouth. For the abbreviated protocol, training was stopped at $25 \mathrm{~min}$ of response time by gently pulling on the seaweed bag until the animal egested the seaweed. Two parameters were recorded during training and testing: (1) the total time that the animals responded and (2) the cumulative time that the animal retained the netted seaweed in its mouth. Testing of the animals occurred using the same procedure with continual presentation of the netted seaweed until 3 min elapsed without the animal taking the seaweed into the mouth. Memory was represented as a decrease in total response time and the time the food was retained in the mouth. Naive animals were handled similarly to trained animals.

Drug treatments. Animals were injected through the anterior portion of the foot with either inhibitor or vehicle at one of three times: $30 \mathrm{~min}$ before the start of training, immediately after the end of training or 30 min before the start of testing ( $3.5 \mathrm{~h}$ after the end of training). No difference in the responses of vehicle-injected and noninjected animals could be discerned for the vehicles used here (ASW and DMSO). To inhibit translation, animals were injected with $1 \mathrm{ml} / 100 \mathrm{~g}$ Aplysia body weight of $3.25 \mu \mathrm{M}$ stock Rapamycin (Biomol-Enzo Life Sciences) in ASW, a dose that approximates $50 \mathrm{~nm}$ systemic concentration in the animal. This calculation is based on Aplysia having an open circulatory system with hemolymph making up $\sim 65 \%$ of their body weight (Levenson et al., 1999). Anisomycin (Sigma-Aldrich) was also used to inhibit translation with injections into the animal of $1 \mathrm{ml}$ of $2 \mathrm{~mm}$ anisomycin in ASW/100 g body weight injected 30 min before training (approximate systemic concentration of $30 \mu \mathrm{M}$ ). Actinomycin D (Calbiochem-EMD Biosciences) was used to inhibit transcription with a $130 \mu \mathrm{l} / 100 \mathrm{~g}$ body weight injection of a $2 \mathrm{~mm}$ stock in DMSO to establish a systemic concentration of $\sim 4 \mu \mathrm{M}$. The PKA inhibitor H89 (Sigma) was used at $1 \mathrm{ml} / 100 \mathrm{~g}$ body weight of $19.5 \mu \mathrm{M}$ stock in ASW. The PKC blocker chelerythrine (Calbiochem-EMD Biosciences) was used at $1 \mathrm{ml} / 100 \mathrm{~g}$ of $43.55 \mu \mathrm{M}$ in ASW. Bisindolylmaleimide (Bis, Calbiochem-EMD Biosciences) was injected at $65 \mu \mathrm{M}$ for a systemic concentration $\sim 1 \mu \mathrm{M}$. To inhibit the MAPK pathway, we used the MEK inhibitor PD98059 (CalbiochemEMD Biosciences) in DMSO at $15 \mathrm{~mm}$ and injected $130 \mu \mathrm{l} / 100 \mathrm{~g}$ animal weight.

Western blotting. Western blotting for P-MAPK and total MAPK was done as previously described (Sharma and Carew, 2002; Sharma et al., 2003b; Michel et al., 2011b). Aplysia were anesthetized by injection of isotonic $\mathrm{MgCl}_{2}$, buccal ganglia dissected and immediately homogenized in lysis buffer (containing, in mu: 50 Tris- $\mathrm{HCl}, \mathrm{pH} 7.6,150 \mathrm{NaCl}, 2 \%$ SDS, 1 EDTA, 1 EGTA, 1 sodium orthovanadate, 50 sodium fluoride and a protease inhibitor cocktail). Samples were centrifuged at $16,000 \times g$ and the supernatant was boiled before storage at $-80^{\circ} \mathrm{C}$. Proteins were resolved via $12 \%$ SDS-PAGE and transferred to PVDF membranes (GE Healthcare). Antibodies for P-MAPK (Cell Signaling Technology) and total MAPK (Erk-1; Santa Cruz Biotechnology) were used. Quantification of P-MAPK was normalized to total MAPK.

Statistics. Statistical analysis of the data was performed using one-way ANOVA with Bonferroni post hoc analyses. $p$ values $<0.05$ were considered significant.

\section{Results \\ Massed training induces a temporally discrete intermediate form of memory}

LFI training using a single massed training session induces robust short and long-term memory with STM decaying by $1 \mathrm{~h}$ (Botzer et al., 1998). Previously, researchers reported that spaced training, but not massed training resulted in ITM $4 \mathrm{~h}$ after training (Botzer et al., 1998). However, it is possible that massed traininginduced ITM was not observed due to either the temporal window examined or potential circadian regulation of ITM. Long-term LFI memory is strongly regulated by the circadian clock (Lyons et al., 2005) and other forms of ITM have also been found to be regulated in a circadian manner (Lyons et al., 2008). We performed a detailed temporal analysis of LFI memory expression after training at Zeitgeber Time 3 (ZT 3; $3 \mathrm{~h}$ after light onset), a time known to induce robust short and long-term LFI memory. As before, we found robust STM 30 min after the end of training with a significant decrease in total response time observed upon testing (Fig. 1A). However, when animals were tested 90 min after training, no memory was observed consistent with previous research indicating the termination of STM $\sim 60$ min after training (Botzer et al., 1998). Similarly, no significant memory was observed $2 \mathrm{~h}$ or $2.5 \mathrm{~h}$ following training with similar response times observed during training and testing (Fig. $1 A$ ). In contrast to previous research, we found robust memory emerging $4 \mathrm{~h}$ after training with animals exhibiting significantly decreased response times compared with training times. This memory, temporally separated from STM, was also evident $6 \mathrm{~h}$ after training (Fig. 1A). Similar results were observed for a second parameter used to assess memory formation, the time animals retained the seaweed in the mouth (data not shown). These results indicate that in addition to STM and LTM, massed training for LFI also induces a robust intermediate form of memory that is temporally separated from STM. Thus, the LFI massed training paradigm provides an ideal opportunity for comparative investigations of the molecular mechanisms underlying short-, intermediate-, and long-term memory.

Because the training time required to reach criterion varies between animals, considerably extended or shortened training between animals prospectively could result in the differential induction of pathways involved in memory formation, i.e., potentially longer training could result in differences in either the magnitude or the temporal window of second messenger cascades. For example, in Aplysia neurons, varying concentrations of serotonin (5-HT) induce differential responses in synaptic excitability (Emptage et al., 1996). Similarly, additional nerve stimulation results in higher levels of 5-HT release (Marinesco and Carew, 2002). Thus, we sought a standardized protocol that would provide a comparable level of training between animals. To enable examination of the molecular pathways underlying $4 \mathrm{~h}$ memory and to more fully map the time course of ITM, we adopted a 25 min standard training protocol. While this is below the mean time observed for animals to train to criterion, the $25 \mathrm{~min}$ training time allowed virtually all animals to receive the allotted training without becoming disinterested, resulting in equivalent training between animals. It should be noted that some minor variance (mean $25.2 \pm 0.18, n=62$ ) occurred in the length 
A
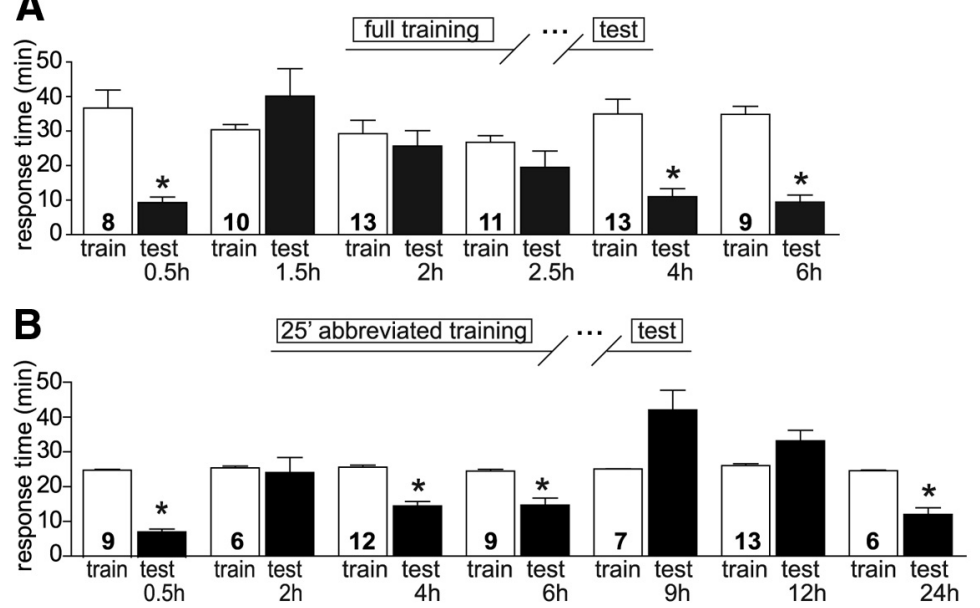

Figure 1. Massed LFI training induces temporally distinct ITM. A, Aplysia californica were individually trained using laver seaweed at ZT 3 to a criterion of 3 min without food entering the buccal cavity. Animals were tested at varying times after training. Memory is represented as a decrease in the total response time to the seaweed during testing and varied significantly based upon the time after training (ANOVA, $F_{(11,127)}=6.767, p<0.001$ ). Animals exhibited robust short-term memory 30 min after training and ITM $4-6 \mathrm{~h}$ post-training. Asterisks indicate significant memory as determined by $p<0.05$ using Bonferroni's Multiple Comparison test post hoc analyses. $N$ for each group as shown in figure. $B, A 25$ min abbreviated training protocol induced significant memory dependent upon the time of testing after training (ANOVA, $F_{(13,123)}=17.8, p<0.001$ ) similar to full-length training. Robust STM was observed $30 \mathrm{~min}$ after training with no memory apparent $2 \mathrm{~h}$ after training. ITM was observed $4-6 \mathrm{~h}$ after training. ITM completely decayed by $9 \mathrm{~h}$ after training. The $25 \mathrm{~min}$ abbreviated training also induced robust LTM evident $24 \mathrm{~h}$ after training.

of the training session (Fig. $1 B$ ) as the netted seaweed had to be extracted from the animal without the exertion of force. Using this protocol, we trained animals at ZT 3 to confirm that the 25 min training protocol resulted in temporal expression of memory comparable to full-length training. Animals trained using the 25 min protocol and tested $30 \mathrm{~min}$ later exhibited robust STM and animals trained and tested $24 \mathrm{~h}$ later demonstrated significantly decreased response times representing LTM. As previously observed with the full training protocol, animals trained for $25 \mathrm{~min}$ and tested $2 \mathrm{~h}$ after training did not exhibit memory. The abbreviated training protocol also induced robust ITM with a similar time course as animals trained to criterion. Testing either 4 or $6 \mathrm{~h}$ after a 25 min training session resulted in significantly decreased response times (Fig. $1 B$ ). However, $9 \mathrm{~h}$ following training there was no evidence of memory. The apparent increase in the animals' response times during testing at $9 \mathrm{~h}$ was not significant compared with responses in naive animals (only tested) or from the training times observed for animals trained to criterion. No memory was observed $12 \mathrm{~h}$ after training similar to previous studies (Botzer et al., 1998). Thus, STM completely decays before the appearance of ITM and ITM decays before the appearance of LTM.

\section{ITM is mechanistically distinct from STM and LTM}

Much of our understanding of the mechanisms underlying ITM arises from meticulous studies of intermediate-term facilitation (ITF) and intermediate-term sensitization of defensive withdrawal reflexes in Aplysia. Nonassociative ITM for facilitation and sensitization requires translation of new proteins (Ghirardi et al., 1995; Sutton et al., 2001; Villareal et al., 2007; Lyons et al., 2008; Antonov et al., 2010). The requirement for protein synthesis in ITM, but not new gene expression, has also been observed in other species including Hermissenda, Lymnaea, and in mammals for long-term potentiation and depression (for review, see Crow et al., 1999; Sangha et al., 2003; Frey and Frey, 2008). However, recently investigators have identified protein synthesis independent forms of ITM for site-specific (associative) sensitization, and dishabituation in Aplysia (Sutton et al., 2004; Antonov et al., 2010). Thus, protein synthesis independent forms of ITM can be generated suggesting a more complex picture of molecular consolidation for some types of learning. In contrast, STM is generally considered independent of protein synthesis as observed for multiple learning paradigms across phylogeny (for review, see Sweatt, 2010). To determine whether short and intermediateterm LFI memory were dependent upon protein synthesis, animals were injected with the local protein translation blocker rapamycin previously used to inhibit translation in Aplysia neuronal cultures and semi-intact preparations (Yanow et al., 1998; Casadio et al., 1999; Purcell et al., 2003; Weragoda et al., 2004; Hu et al., 2006). Rapamycin regulates the TOR (target of rapamycin) pathway leading to translation and has been shown to rapidly and significantly reduce protein synthesis in Aplysia cells and ganglia preparations at concentrations slightly lower than used in our experiments (Yanow et al., 1998; Casadio et al., 1999). Rapamycin itself had no effect on feeding response behavior as seen through comparisons of the training response times between inhibitor and vehicle-treated animals (Fig. 2A,B). Using the $25 \mathrm{~min}$ training protocol, we found that STM was unaffected by rapamycin with treated and control animals demonstrating robust memory 30 min after training (Fig. 2 A) suggesting that short-term LFI memory was not dependent upon protein synthesis. However, recent studies in Aplysia elegantly demonstrated that facilitation and sensitization spanning similar time frames required protein synthesis (Villareal et al., 2007; Antonov et al., 2010). To further investigate whether short-term LFI memory required protein synthesis, animals were injected with anisomycin. Animals treated with anisomycin $30 \mathrm{~min}$ before training demonstrated robust STM (Control Animals $(n=11)$ : Training Time = $24.63 \pm 0.18$, Testing Time $=9.02 \pm 1.109$; Anisomycin-Treated Animals $(n=9)$ : Training Time $=23.62 \pm 0.96$, Testing Time $=$ $6.05 \pm 0.80$; ANOVA, $\left.F_{(3,39)}=132.2, p<0.001\right)$. These results suggest that while short-term LFI memory may span a similar time frame to that observed for protein synthesis-dependent nonassociative facilitation and sensitization, the temporal windows for short and intermediate-term memories vary between types of learning and learning paradigms.

In contrast to the results observed for STM, ITM at $4 \mathrm{~h}$ was completely abolished by rapamycin injection with testing times in treated animals similar to training times (Fig. $2 B$ ) suggesting that intermediate-term LFI memory requires protein synthesis. It was not possible to confirm these results using anisomycin as the animals were nonresponsive to the presentation of the seaweed during the ITM test $(0 / 17$ animals responded to the seaweed within $10 \mathrm{~min}$; data not shown) suggesting that anisomycin resulted in a suppression of feeding responses during the time frame spanning ITM. Previous research found that anisomycin treatment in Lymnaea resulted in decreased feeding responses (Fulton et al., 2005). As an additional measure to assess the affect 
of anisomycin on feeding, animals were injected with anisomycin and presented with romaine lettuce at time points comparable to either the start of STM testing (90 min after injection) or the start of ITM testing ( $5 \mathrm{~h}$ after injection). At $90 \mathrm{~min}$ after injection, $\sim 77 \%$ of treated animals ( $n=9$; data not shown) responded to lettuce within $1 \mathrm{~min}$ comparable to responses observed in noninjected animals. In contrast, $5 \mathrm{~h}$ after injection zero animals responded to the lettuce within 5 $\min (n=4$; data not shown) similar to the lack of responsiveness during seaweed presentation for ITM testing. Therefore, anisomycin could not be used to evaluate the inhibition of protein synthesis on ITM due to the suppression of feeding responses. However, based upon our results with rapamycin, it appears that intermediate-term LFI memory is both temporally and mechanistically separated from STM.

Increased mRNA expression for the immediate-early gene $A p C / E B P$ occurs within $1 \mathrm{~h}$ after LFI training with significant increases in protein levels observed $2 \mathrm{~h}$ after training in neurons of the buccal ganglia (Levitan et al., 2008). Given the 4-6 h time frame for intermediate-term LFI memory, it is possible that this form of ITM requires transcription as well as translation. We tested the requirement for transcription in LFI memory using the transcription inhibitor actinomycin D, previously used in Aplysia cell-culture and semi-intact preparations (Castellucci et al., 1986; Bailey et al., 1992; Sutton et al., 2001). Animals were injected 30 min before training with either vehicle or actinomycin D (130 $\mu \mathrm{l} / 100 \mathrm{~g}$ body weight injection of a $2 \mathrm{~mm}$ stock in DMSO approximating $4 \mu \mathrm{M}$ systemic concentration). Both treated and vehicleinjected animals showed robust ITM when tested $4 \mathrm{~h}$ after training (Fig. 2C). Similar experiments were performed using a higher concentration of actinomycin D (130 $\mu \mathrm{l} / 100 \mathrm{~g}$ body weight injection of a $4 \mathrm{~mm}$ stock in DMSO resulting in $\sim 8 \mu \mathrm{M}$ systemic concentration) to confirm these results. The $8 \mu \mathrm{M}$ systemic concentration of actinomycin D had no effect on ITM with results similar to those presented in Figure 2C (Control Animals $(n=7)$ : Training Time $=25.58 \pm 0.23$, Testing Time $=13.05 \pm$ 1.56; Actinomycin D-treated Animals $(n=9)$ : Training Time $=$ $26.75 \pm 0.76$, Testing Time $=14.33 \pm 3.48$, ANOVA, $F_{(3,31)}=$ $11.48, p<0.001)$. As a control, we verified that actinomycin D (4 $\mu \mathrm{M}$ systemic concentration) blocked long-term LFI memory by injecting the animals 30 min before training and testing them $24 \mathrm{~h}$ later. For these LTM experiments, animals were trained using the full-length training protocol similar to previous studies resulting in longer training times as shown in Figure $2 D$. Injection of actinomycin D blocked long-term memory while control animals demonstrated robust memory with significantly decreased response times (Fig. $2 \mathrm{D}$ ). The $8 \mu \mathrm{M}$ systemic concentration of actinomycin D was not repeated in LTM experiments as the higher dose rendered many animals unresponsive to the test stimulus $24 \mathrm{~h}$ after injection. Presumably, this effect is due to the irreversible nature of actinomycin D as an inhibitor of transcrip- tion. A comparable effect of the drug has previously been observed in Lymnaea in which $24 \mathrm{~h}$ after actinomycin treatment, animals become unresponsive to sucrose (Fulton et al., 2005). These results demonstrate that ITM induced by a massed training protocol is mechanistically, as well as temporally, differentiated from both STM and LTM.

\section{PKA activity is necessary for the induction and expression of ITM}

Consistently across learning paradigms and species, induction of memory requires the activation of second messenger signaling cascades and increased kinase activity (for review, see Sweatt, 2010). While brief activation of these cascades often is sufficient for STM, temporally longer forms of memory require the persistent activation of kinases. The CAMP-PKA cascade has been implicated in memory formation in Aplysia (for review, see Burrell and Sahley, 2001; Kandel, 2001), Drosophila (for review, see Davis, 2005), and mammals (for review, see Abel and Nguyen, 2008). On a short-term timescale, PKA phosphorylates substrates local to the synapse leading to covalent modifications involved in STM. Over a longer time frame, a persistently active catalytic subunit can translocate to the nucleus frequently resulting in activation of the transcription factor CREB and subsequent gene transcription (for review, see Bailey et al., 2008; Sweatt, 2010). For intermediate-term, protein synthesis-dependent sensitization in Aplysia, persistent PKA activity has been identified as an additional requirement for the maintenance and expression of memory (Sutton and Carew, 2000; Stough et al., 2006). We investigated the role of PKA for intermediate-term LFI memory 

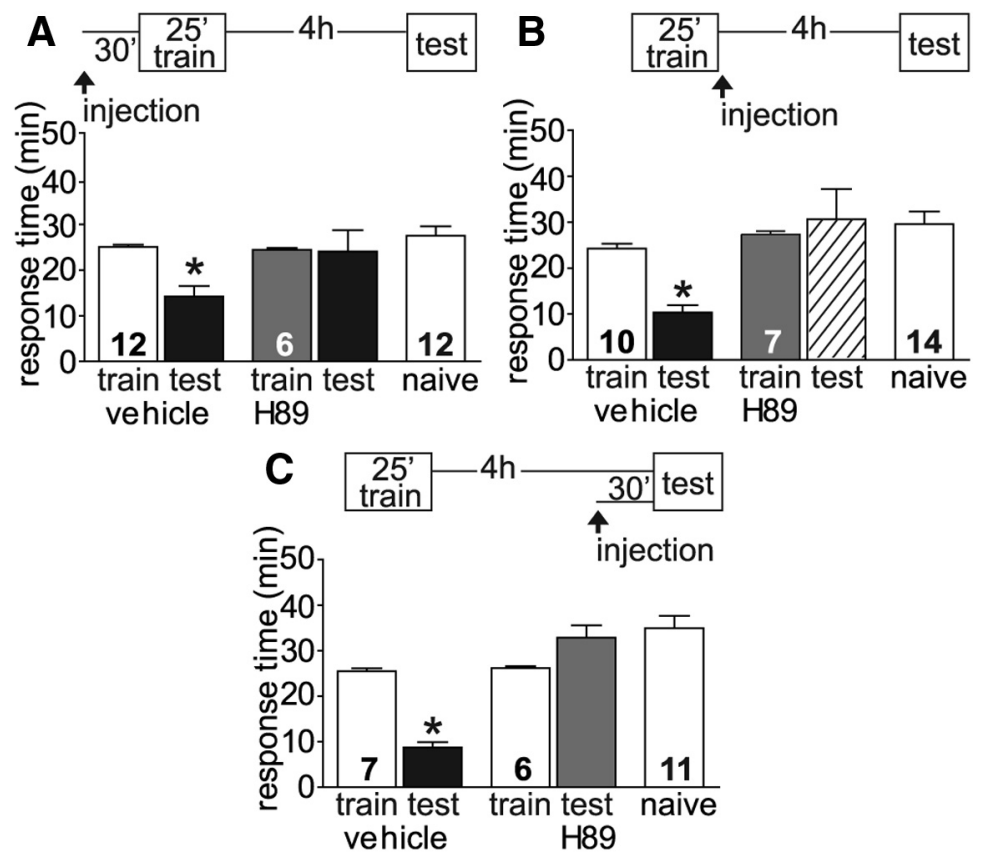

Figure 3. PKA activity is necessary for the induction and maintenance of ITM. $A$, The PKA inhibitor H89 or vehicle was injected $30 \mathrm{~min}$ before training. Vehicle-injected animals demonstrated robust ITM upon testing while $\mathrm{H} 89$ animals exhibited no decrease in response times similar to naive animals $\left(F_{(4,47)}=6.853, p<0.001\right)$. B , H89 administered after LFI training also blocked ITM while vehicle-injected animals exhibited decreased response times compared with training times or naive animals (ANOVA, $\left.F_{(4,47)}=8.211, p<0.001\right)$. C, To test whether PKA activity was needed for maintenance the entire length of ITM or for recall, animals were injected with vehicle or $\mathrm{H} 8930 \mathrm{~min}$ before testing. Control animals demonstrated significant ITM with response times significantly decreased compared with training times or naive animals, while $\mathrm{H} 89$ animals exhibited no ITM with response times similar to naive animals (ANOVA, $F_{(4,36)}=23.57, p<0.001$ ). $N$ for each group as shown in figure. Asterisks indicate $p<$ 0.05 for post hoc analyses using Bonferroni's Multiple Comparison test.

using the PKA inhibitor H89 previously used in Aplysia cell cultures (Farah et al., 2009) and in vivo to study long-term memory (Michel et al., 2011a). We inhibited PKA activity during the induction phase of memory formation by injecting H89, 30 min before training. ITM was completely inhibited in injected animals compared with vehicle-injected control animals (Fig. 3A). As previously reported (Michel et al., 2011a), injection of inhibitor did not affect the baseline responses of the animals as no differences were seen in training responses between treated and control animals. These results suggest that PKA activity is necessary for the induction of ITM similar to what was previously observed for LTM. To differentiate between the requirement for PKA activity during the early stages of memory formation and the possibility of an extended role for PKA during the molecular consolidation or maintenance of memory, $\mathrm{H} 89$ was injected into animals immediately after training. Vehicle-injected control animals demonstrated robust ITM when tested $4 \mathrm{~h}$ after training, while inhibitor-injected animals exhibited no memory with response times similar to naive animals (Fig. 3B). Moreover, when the PKA inhibitor was injected $3.5 \mathrm{~h}$ after training (30 min before testing), animals likewise demonstrated no LFI memory (Fig. 3C). Overall, these studies suggest that LFI training results in persistently active PKA and that PKA occupies an essential role in the induction and maintenance of intermediate-term LFI memory.

\section{PKC activity is necessary for the induction and maintenance of ITM}

PKC, another serine-threonine kinase, has been shown essential for memory formation in Aplysia (for review, see Sossin, 2007), olfactory memory in Apis (Grünbaum and Müller, 1998), operant conditioning in Lymnaea (Rosenegger and Lukowiak, 2010), the induction and maintenance of LTP (for review, see MacDonald et al., 2001; Sacktor, 2008) and contextual fear conditioning (Atkins et al., 1998; Weeber et al., 2000). In Aplysia, three different neuronal PKC isoforms have been identified with Apl I representing a classical, $\mathrm{Ca}^{2+}$ activated PKC; Apl II, a novel form of PKC dependent upon diacylglycerol but not $\mathrm{Ca}^{2+}$; and Apl III classified as an atypical PKC that requires neither diacylglycerol nor $\mathrm{Ca}^{2+}$ (Kruger et al., 1991; Bougie et al., 2009; for review, see Sossin, 2007). PKCs can be activated via multiple mechanisms including calcium signaling, phosphorylation and cleavage (for review, see Sossin, 2007). Persistently activated forms of PKC in Aplysia (PKM), arise through proteolytic cleavage by calpain (Sharma and Carew, 2002; Villareal et al., 2009; Cai et al., 2011) as opposed to rapid synthesis as observed in mammals (Osten et al., 1996). Calpain-dependent persistently active $\mathrm{PKC}$ is required for site-specific intermediate-term facilitation (Sutton et al., 2004) and for maintenance of long-term sensitization in Aplysia (Cai et al., 2011).

We investigated the involvement of PKC in intermediate LFI memory with chelerythrine, an inhibitor of PKC, using a dosage previously shown to inhibit the induction of long-term in vivo LFI memory with no effect on baseline responses of the animal (Michel et al., 2011a). When chelerythrine was injected $30 \mathrm{~min}$ before training, approximated systemic concentration of $670 \mathrm{nM}$, the inhibitor completely blocked ITM while vehicle-injected controls demonstrated robust memory with significantly decreased response times (Fig. 4A). Chelerythrine inhibits all isoforms of PKC but is selective for persistently active PKM Apl III at low concentrations with little effect on PKC Apl II or PKC Apl III (Sossin, 2007; Villareal et al., 2009; Cai et al., 2011). To further test the specific isoforms of PKC necessary for the induction of intermediateterm LFI memory, animals were treated with the inhibitor Bis, which at low concentrations $(1 \mu \mathrm{M})$ selectively inhibits PKC Apl II (Villareal et al., 2009). Bis does not effectively inhibit PKC Apl III and significantly higher concentrations than $1 \mu \mathrm{M}$ are required for inhibition of PKM Apl III (Sossin, 2007; Villareal et al., 2009). Animals injected 30 min before training with Bis, at a systemic concentration approximating $1 \mu \mathrm{M}$, demonstrated no ITM when compared with vehicle-injected control animals (Fig. 4B). In Aplysia, pharmacological inhibition of PKC activity is reported to be similar for PKC Apl I and PKC Apl II as PKC inhibitors which show selectivity in mammals do not distinguish between PKC Apl I and PKC Apl II (Manseau et al., 2001; for review, see Sossin, 2007). PKC Apl I and PKC Apl II are both required for short- and intermediate-term facilitation (Zhao et al., 2006). Our results similarly suggest that multiple isoforms of PKC are required for the induction of intermediate-term LFI memory.

To test the requirement for PKC activity during the maintenance of ITM, chelerythrine was injected immediately after the 
end of LFI training. Treated animals failed to display any memory with response times similar to those observed in naive animals (Fig. 4C) suggesting that PKM Apl III also functions in the maintenance of ITM. Vehicle-injected animals exhibited robust ITM with significantly decreased response times compared with training times or naive responses (Fig. 4C). To determine whether PKC Apl I/II also is required for the maintenance of ITM, additional experiments were performed in which animals were injected with Bis immediately after training and tested $4 \mathrm{~h}$ later. Bis-injected animals demonstrated robust ITM comparable to control animals (Fig. 4D). These results suggest that whereas multiple isoforms are required for the induction of ITM, only PKM Apl III is required for its maintenance. To further investigate the role of PKM Apl III in the maintenance of ITM, animals were injected with chelerythrine $30 \mathrm{~min}$ before testing ( $3.5 \mathrm{~h}$ after end of training, Fig. $4 E$ ). Treated animals exhibited no ITM, while control animals displayed robust ITM. These experiments demonstrate the necessity of persistent PKC concomitant with protein synthesis and PKA activity in the induction and maintenance of ITM. This contrasts with previous results finding that persistent PKC activity was not required for maintenance of LTM when chelerythrine was injected immediately after training (Michel et al., 2011a).

Given that ITM appears to require persistent PKM Apl III for an extended period of time for maintenance of memory, the possibility exists that PKC Apl III is cleaved and PKM Apl III released at a later time-point and thereby still needed for LTM maintenance. To test for this possibility, animals were trained using the full-length protocol comparable to the previous LTM experiments (Michel et al., 2011a) and then injected with chelerythrine $1 \mathrm{~h}$ after training, a time point in which memory is not expressed but the molecular changes associated with longterm memory including MAPK signaling and the induction of gene expression and protein synthesis are occurring (Levitan et al., 2008; Michel et al., 2011b). Animals injected with chelerythrine demonstrated robust LTM comparable to control animals (Fig. $4 F$ ), supporting previous research (Michel et al., 2011a) that persistent PKC, at least the PKM Apl III isoform, is not required for long-term LFI. However, recent research on longterm sensitization demonstrated that well established sensitization can be disrupted
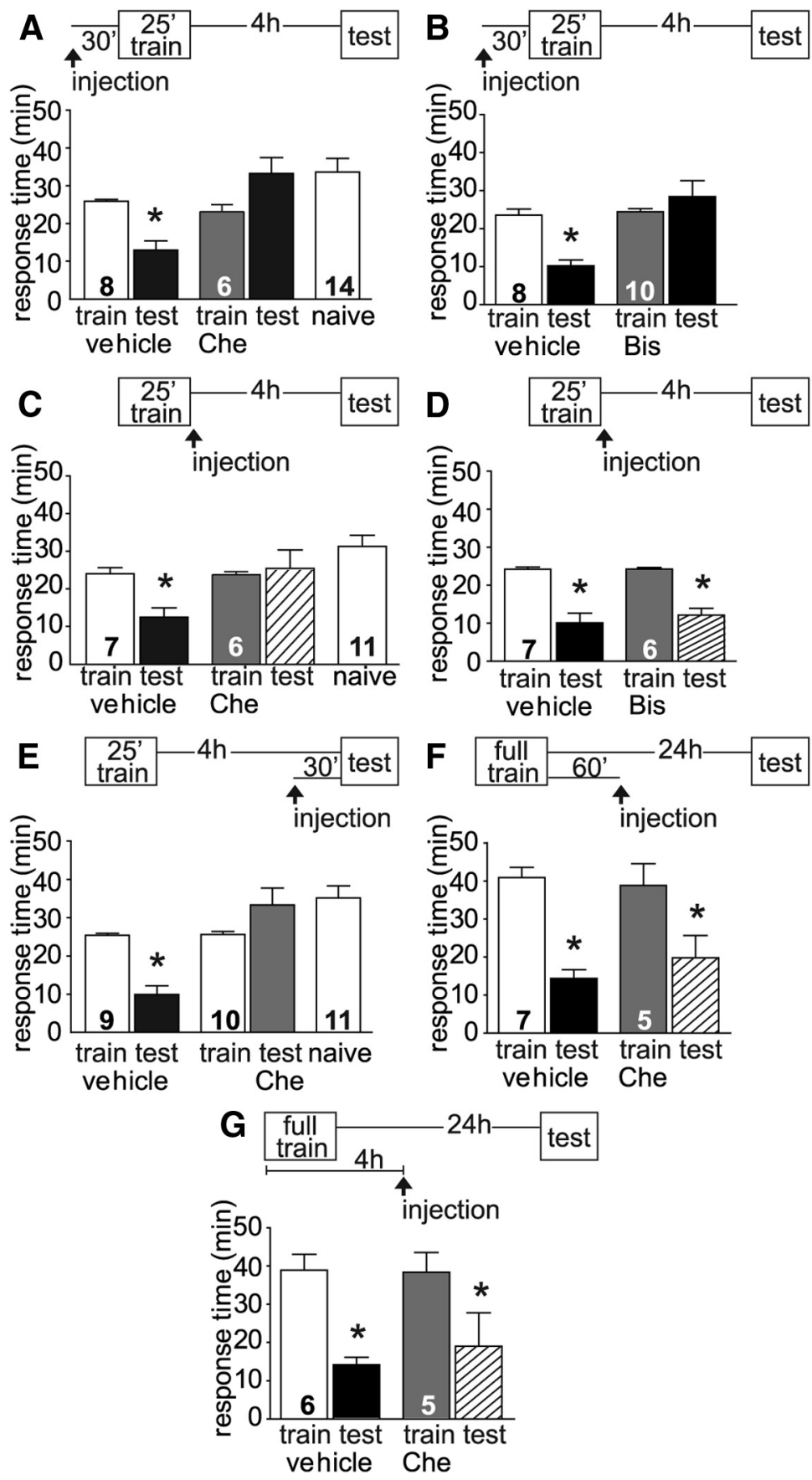

Figure 4. PKC is required for the induction and maintenance of ITM. $A$, Chelerythrine, an inhibitor of PKC, injected 30 min before training blocked ITM with response times during testing similar to naive animals. Vehicle-injected animals demonstrated significantly decreased response times and robust ITM (ANOVA, $\left.F_{(4,41)}=6.936, p<0.001\right)$. B, Bisindolylmaleimide, an inhibitor of PKC Apl II, injected $30 \mathrm{~min}$ before training also completely blocked ITM with responses comparable to naive animals. Vehicle-injected animals demonstrated significantly decreased response times and robust ITM (ANOVA, $\left.F_{(3,35)}=9.087, p<0.001\right)$. C, Chelerythrine injected into animals post-training $(n=6)$ also blocked ITM, while vehicle-injected animals exhibited robust ITM (ANOVA, $\left.F_{(4,36)}=5.879, p<0.01\right)$. D, Bis injected into animals immediately after training $(n=6)$ did not inhibit ITM with treated animals demonstrating significant ITM similar to vehicle-injected $(n=7)$ animals (ANOVA, $F_{(3,25)}=21.77, p<0.001$ ). $\boldsymbol{E}$, To test whether PKC was needed for maintenance the entire length of ITM, animals were injected with vehicle or chelerythrine 30 min before testing. Control animals demonstrated significant ITM with response times significantly decreased compared with training times or naive animals. Chelerythrine-treated animals exhibited no ITM with response times similar to naive animals (ANOVA, $F_{(4,48)}=$ $12.72, p<0.001)$. N for each group as shown in figure. Asterisks indicate $p<0.05$ for post hoc analyses using Bonferroni's Multiple Comparison test. $\boldsymbol{F}$, Chelerythrine injected into animals $1 \mathrm{~h}$ post-training had no effect on LTM, with drug- and vehicle-injected animals exhibiting comparable LTM with significantly decreased response times (ANOVA, $F_{(3,23)}=12.09, p<0.001$ ). $\mathbf{G}$, Chelerythrine injected into animals $4 \mathrm{~h}$ after the start of training also did not inhibit LTM, with drug-and vehicle-injected animals exhibiting comparable LTM with significantly decreased response times (ANOVA, $F_{(3,21)}=6.23, p<0.01$ ). 

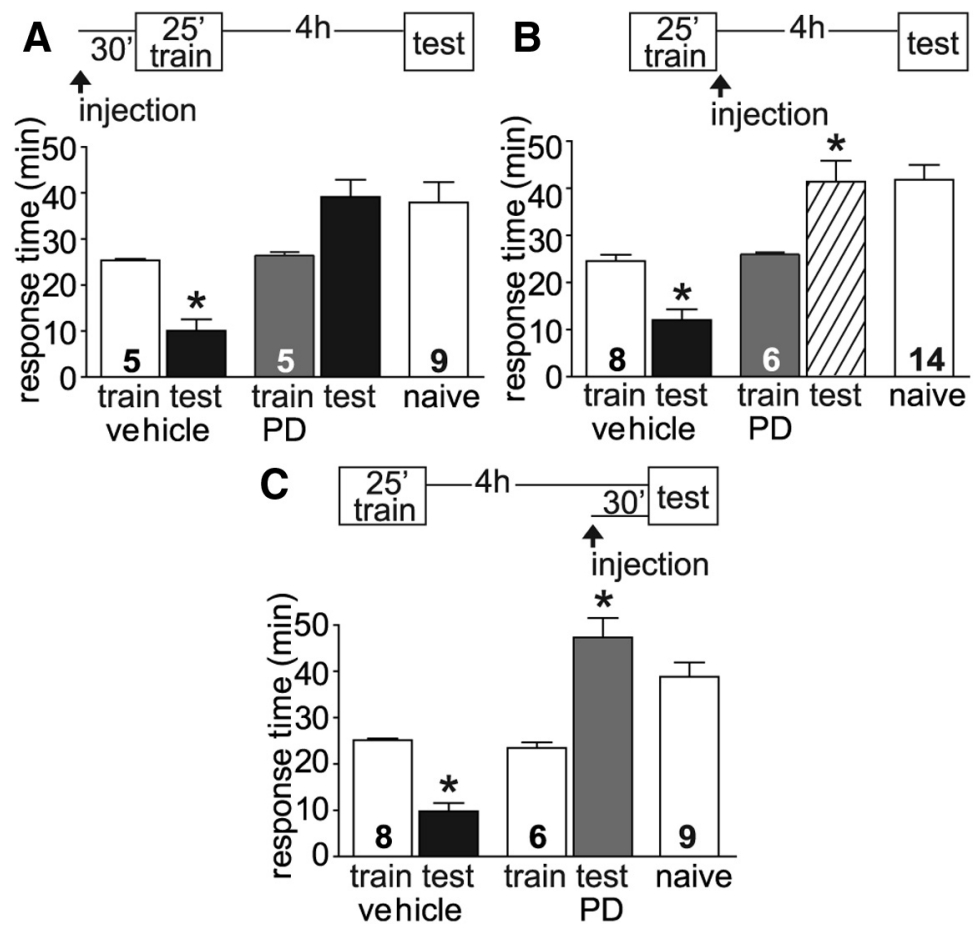

Figure 5. MAPK is necessary for ITM. $\boldsymbol{A}$, To determine whether MAPK activation was necessary for ITM, the MEK inhibitor PD98059 was injected 30 min before LFI training. Upon testing $4 \mathrm{~h}$ after training, vehicle-injected animals demonstrated robust ITM with significantly decreased response times compared with training responses (ANOVA, $F_{(4,28)}=10.14, p<0.001$ ). In contrast, PD98059-injected animals exhibited response times similar in length to naive animals. $\boldsymbol{B}$, MAPK is also required after training as PD98059 injected into animals post-training blocked ITM with response times similar to naive animals. Vehicle-injected animals exhibited significant ITM (ANOVA, $\left.F_{(4,41)}=18.73, p<0.001\right)$. C, To determine whether MAPK was needed for maintenance the entire length of ITM, animals were injected with vehicle or PD9805930 min before testing. Control animals demonstrated significant ITM with response times significantly decreased compared with training times or naive animals, while PD98059-treated animals exhibited no ITM with response times similar to or greater than naive animals (ANOVA, $\left.F_{(4,36)}=33.45, p<0.001\right)$. Testing times of PD98059-treated animals were significantly greater than training times $(\boldsymbol{B}, \boldsymbol{C})$ as the abbreviated training protocol of $25 \mathrm{~min}$ was used in these experiments. $N$ for each group as shown in figure. Asterisks indicate $p<0.05$ for post hoc analyses using Bonferroni's Multiple Comparison test for training versus testing response comparisons.

by chelerythrine at later times after training indicating that continual PKM Apl III phosphorylation activity is necessary for the maintenance of long-term memory (Cai et al., 2011). To determine whether this requirement applies to long-term LFI memory, we trained animals using the full-length training protocol and then injected them with chelerythrine $4 \mathrm{~h}$ after the start of training, a time point approximating the time of injection for the extended maintenance experiments for ITM shown in Figure $4 E$. At this time point, the processes involved in long-term memory formation are well underway with the induction of gene expression and protein synthesis already occurring (Levitan et al., 2008). In contrast to long-term sensitization and intermediateterm LFI, we found that PKM Apl III was not required during this later time window for maintenance of long-term LFI as animals injected with chelerythrine $4 \mathrm{~h}$ after the start of training exhibited significant long-term LFI memory similar to control animals (Fig. 4G). We performed confirmation experiments in which chelerythrine was injected into the animals $4 \mathrm{~h}$ after the end of training and as predicted these animals demonstrated long-term memory with a mean percentage decrease in total response time between training and testing of $45 \%(n=3$, data not shown). Thus, mechanistic differences exist between the maintenance of ITM and the maintenance of LTM specifically in the requirement for persistent PKC activity.

\section{MAPK signaling is required for ITM}

The above results strongly suggest that PKA and PKC signaling cascades fulfill a large role in the induction and maintenance of ITM for negatively reinforced operant conditioning. However, MAPK signaling has been shown necessary for the induction of short-term and longterm LFI memory (Michel et al., 2011b). MAPK signaling also is required for longterm synaptic plasticity in many paradigms including facilitation and sensitization in Aplysia (Martin et al., 1997; Purcell et al., 2003; Sharma et al., 2003b), olfactory memory in Drosophila (Moressis et al., 2009; Pagani et al., 2009) and associative memory in mammals (for review, see Sweatt, 2010). Furthermore, MAPK activity is necessary for some forms of ITM in Aplysia including sensitization and facilitation (Sharma et al., 2003a,b; Lyons et al., 2008; Shobe et al., 2009), and operant conditioning of aerial respiratory behavior in Lymnaea (Rosenegger and Lukowiak, 2010). Because MAPK represents a potential convergence point for multiple signaling pathways, we examined the necessity of MAPK in intermediate-term LFI memory. We used the specific MEK inhibitor PD98059 previously used in Aplysia in vivo (Lyons et al., 2008; Michel et al., 2011b) and in vitro (Bailey et al., 1997; Martin et al., 1997; Khabour et al., 2004). Inhibition of MAPK before training completely blocked ITM while vehicle-injected animals exhibited significant memory (Fig. 5A). Testing times of PD98059-treated animals were greater than training times as the abbreviated training protocol of $25 \mathrm{~min}$ was used in these experiments. However, the total response times of PD98059treated animals were not significantly different from response times for naive animals (all panels, Fig. 5) indicating that PD98059 did not by itself induce increased feeding responses. Prolonged MAPK signaling also was required for ITM, as injection of the inhibitor immediately after training (Fig. $5 B$ ) prevented the observation of ITM $4 \mathrm{~h}$ after training similar to the requirement for sustained MAPK signaling previously observed for long-term LFI memory (Michel et al., 2011b). MAPK activity also was necessary for the extended maintenance or expression of ITM as injection of PD98059 30 min before testing blocked memory with response times observed greater than or equivalent to training and the responses of naive animals (Fig. 5C). Thus, it appears that in vivo LFI training for negatively reinforced operant learning engages an assemblage of signaling cascades that are necessary for the induction and maintenance of ITM.

\section{Prolonged phase of MAPK activation depends upon protein} synthesis, but not PKA or PKC activity

Following LFI training, the activation of MAPK in the buccal ganglion occurs in two waves of activity (Michel et al., 2011b), an immediate phase necessary for all temporal forms of memory and a second wave of MAPK activity evident $1 \mathrm{~h}$ after training that is 
required for ITM and LTM. To identify the interrelationship between the signaling cascades necessary for ITM, we examined the requirements for activation of the later wave of MAPK. Previously, we found that the later phase but not immediate MAPK activation was, at least in part, dependent upon PKG activity (Michel et al., 2011b). In Aplysia, sustained MAPK activation necessary for LTM that is observed $1 \mathrm{~h}$ after training requires protein synthesis (Shobe et al., 2005). To determine whether MAPK activation $1 \mathrm{~h}$ after training was dependent upon protein synthesis, animals were injected with rapamycin $30 \mathrm{~min}$ before LFI training. Animals were dissected $1 \mathrm{~h}$ following training, protein extracted from buccal ganglia and Western blotting performed to measure phospho-MAPK levels. Rapamycin injected into animals before training significantly inhibited the traininginduced activation of MAPK (Fig. 6A). Previously, it has been suggested that MAPK activation may lie downstream of the cAMP-PKA pathway in LTM (Martin et al., 1997). To determine whether the prolonged or second phase of MAPK activation required PKA activity, animals were injected with H89 30 min before training. As described previously, animals were dissected $1 \mathrm{~h}$ after training and phospho-MAPK and total MAPK levels analyzed in buccal ganglia. H89 had no effect on the traininginduced increase in MAPK activation evident $1 \mathrm{~h}$ after training (Fig. 6B). In similar experiments, we found that chelerythrine also did not block the training-induced prolonged phase of MAPK activation (Fig. $6 \mathrm{C}$ ). These experiments strongly suggest that protein synthesis, but neither PKA nor PKC activity is necessary for sustained MAPK activation required for ITM and LTM.

\section{Discussion}

Studies of the molecular mechanisms underlying temporally distinct memories have frequently relied upon variations in training to induce short-, intermediate-, or long-term memory as for sensitization in Aplysia (Mauelshagen et al., 1996, 1998) or operant conditioning in Lymnaea (Lukowiak et al., 2000). However, use of differential induction protocols potentially results in significant variations in recruitment of signaling cascades or pathways for induction and storage of memory. To allow for direct comparison of the mechanisms underlying temporally distinct forms of memory in vivo, we used a negatively reinforced operant learning paradigm that results in robust STM and LTM to identify and characterize a massed training-induced temporally distinct ITM. Intermediate LFI memory was mechanistically discrete from STM and LTM with dependence upon protein synthesis, but not transcription. The sensitivity of ITM to inhibition with rapamycin suggests a requirement for synaptic protein synthesis as rapamycin has been linked to protein synthesis localized at the synapse, and other forms of ITM in Aplysia require local protein synthesis (Sherff and Carew, 2004; Villareal et al., 2007).

The question arising from identification of temporally sequential memories is whether the molecular mechanisms supporting these memories occur in serial progression or whether the signaling cascades underlying these forms of memory develop in parallel and, to some extent, independently. Defining the signaling mechanisms underlying distinct forms of memory using a single induction protocol is pivotal to understanding memory formation in vivo and for insight into the complex array of molecular changes induced during learning. To delineate the temporal relationship between the signaling pathways involved in ITM and other memory phases, we analyzed the requirements for three highly conserved kinases implicated in learning across phyla: PKA, PKC and MAPK. We found differences in the kinases
A
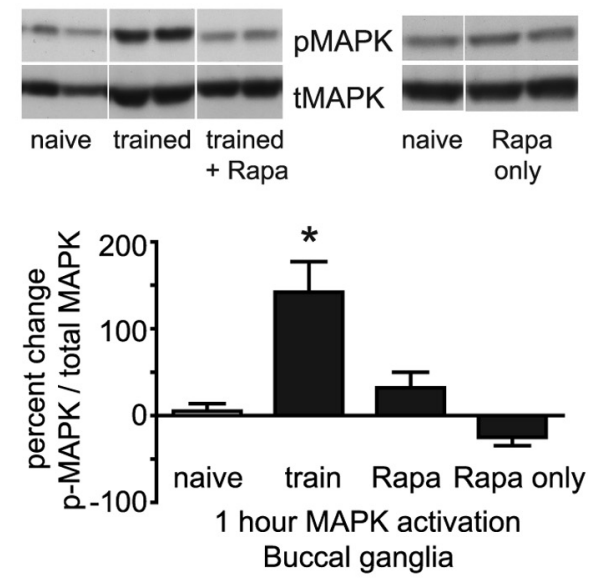

B
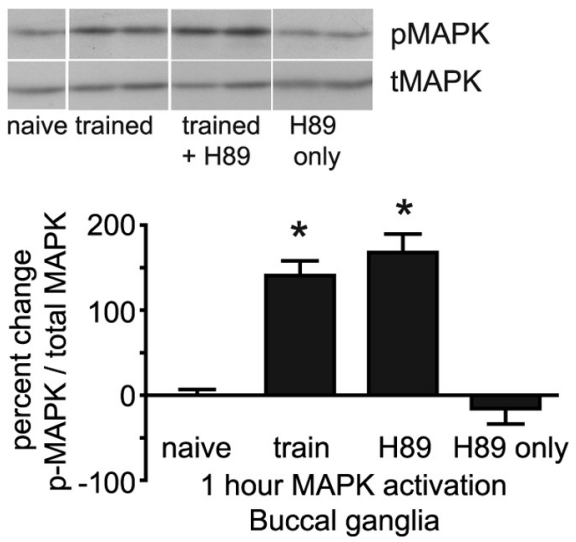

C
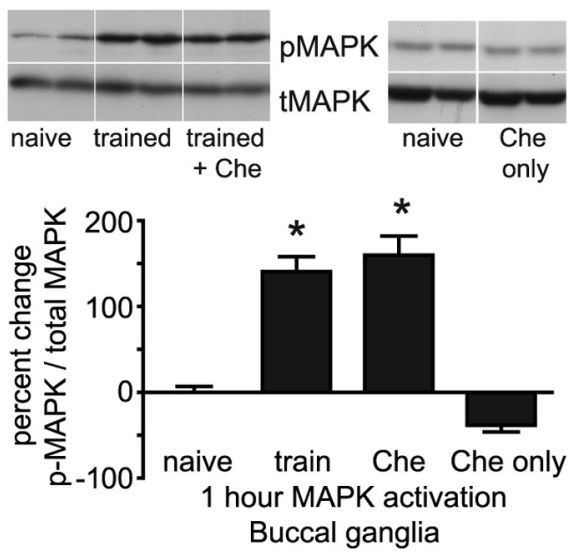

Figure 6. Prolonged phase of MAPK activation requires protein synthesis, but not PKA or PKC activity. $\boldsymbol{A}$, The prolonged phase of MAPK activation induced by LFI training was significantly decreased by inhibition of protein synthesis. Animals receiving LFI training $(n=8)$ exhibited significantly higher levels of phospho-MAPK in buccal ganglia $1 \mathrm{~h}$ after training compared with animals treated with rapamycin before training $(n=9)$, naive animals $(n=11)$ or rapamycin injections only ( $n=7$ ) without training (ANOVA, $F_{(3,34)}=12.51, p<0.001$, Bonferroni post hoc analyses). Representative examples from Western blots are shown above the graphs. $\boldsymbol{B}$, Inhibition of PKA activity through $\mathrm{H} 89$ injected in animals before training had no effect on MAPK activation $1 \mathrm{~h}$ after training. Animals treated with $\mathrm{H} 89$ before training $(n=14)$ or animals receiving only training $(n=12)$ showed significantly increased levels of phospho-MAPK in the buccal ganglia $1 \mathrm{~h}$ after LFI training compared with naive animals $(n=10)$ or $\mathrm{H} 89$-treated animals that did not receive training $(n=6$; ANOVA, $\left.F_{(3,41)}=23.74, p<0.001\right)$. C, Inhibition of PKC before training had no effect on phosphoMAPK levels $1 \mathrm{~h}$ after training. Animals treated with chelerythrine before training $(n=6)$ or animals receiving only training $(n=12$ ) showed significantly increased levels of phospho-MAPK in the buccal ganglia $1 \mathrm{~h}$ after LFI training compared with naive animals $(n=10)$ or chelerythrine-injected animals that did notreceivetraining $\left(n=4 ;\right.$ ANOVA, $\left.F_{(3,31)}=31.66, p<0.001\right)$. Asterisks represent $p<0.05$ Bonferroni post hoc analyses for trained animals compared with naive or drug-alone groups. 
required between ITM and STM, and importantly, significant differences were observed for the required window of activity in vivo for each kinase pathway between ITM and LTM suggesting that the mechanisms underlying temporally distinct LFI memories occur, at least in part, in parallel rather than in serial progression.

Recently, long-term LFI memory but not STM was shown dependent upon PKA (Michel et al., 2011a), with persistent PKA activation resulting in CREB-dependent transcription of immediate early genes following LFI training (Levitan et al., 2008). In this study using H89 to inhibit PKA activity, persistent PKA activity appears necessary for induction and maintenance of ITM as inhibitors given before training to $30 \mathrm{~min}$ before testing blocked ITM. Although H89 is considered relatively selective for PKA, H89 also inhibits mitogen and stress activated protein kinase 1, Rho-dependent protein kinase II and p70 ribosomal protein S6 kinase (Davies et al., 2000). Because these kinases have been implicated in plasticity in other learning paradigms (Udo et al., 2005; Chwang et al., 2007; Sindreu et al., 2007), the possibility exists that ITM also may require these kinases. While our results suggest that PKA is necessary for an extended period of time for maintenance of ITM, it remains possible that PKA functions during recall of memory. However, we find this scenario unlikely as recall in STM and LTM did not require PKA for expression of LFI memory (Michel et al., 2011a). The relatively long window of persistent PKA activity in ITM may be integrated with protein synthesis. In Aplysia facilitation, spaced 5-HT pulses, but not massed training, induced persistent intermediate PKA activity dependent upon protein synthesis (Müller and Carew, 1998; Sutton and Carew, 2000). The longer requirement for persistent PKA in massed training-induced ITM highlights significant mechanistic differences between ITM and LTM.

Strikingly, ITM requires the persistence of multiple signaling cascades concurrent with protein synthesis. We found that PKC activity was necessary for induction and maintenance of intermediate-term LFI memory. Previously, PKC-dependent inhibition of translation was suggested as a mechanism for the decreased efficacy of massed training for long-term facilitation (Farah et al., 2009). However, we found that the PKM isoform of Apl III appears necessary for induction and maintenance of intermediate-term LFI as a low dosage of chelerythrine blocked ITM when administered before or after training. Moreover, the induction of ITM appears to require additional isoforms of PKC as $1 \mu \mathrm{M}$ Bis, a concentration that should not inhibit PKC Apl III or PKM Apl III, blocked ITM only when administered before training. These results are consistent with 5-HT-induced synaptic plasticity in which chelerythrine and Bis inhibited induction of the 5-HT enhancement of glutamate-evoked postsynaptic potentials, while only chelerythrine blocked maintenance (Villareal et al., 2009). In contrast, the lack of required PKM Apl III activity for maintenance of long-term LFI (Fig. 4F, G; Michel et al., 2011a) differs dramatically from long-term sensitization (Cai et al., 2011) highlighting the difference between long-term maintenance of operant memory and nonassociative sensitization.

Several possible functions exist for PKC during LFI memory formation. Initially, PKC activity during ITM and LTM may enhance PKA signaling as suggested for operant reward memory (Lorenzetti et al., 2008) while persistent PKC at the plasma membrane could regulate neurotransmitter release as suggested for sensory-motor synapses (Ghirardi et al., 1995; Houeland et al., 2007). Furthermore, MAPK activity may affect PKC as proposed for activity-dependent ITF in which MAPK induces PKC translocation to the plasma membrane (Shobe et al., 2009).
MAPK represents an important integrator for neuronal inputs with conveyance to multiple targets to facilitate synaptic plasticity (for review, see Selcher et al., 1999; Reissner et al., 2006) or activate translational machinery (Kelleher et al., 2004). MAPK is required for the induction of ITF (Sharma et al., 2003a) and intermediate-term sensitization (Lyons et al., 2008) and ITM in Lymnaea (Rosenegger and Lukowiak, 2010). Previously, we determined that MAPK activity was necessary for induction of short and long-term LFI with prolonged MAPK activity necessary for LTM (Michel et al., 2011b). Presumably, the requirement of sustained MAPK in LTM reflects nuclear MAPK translocation and resultant CREB-dependent transcription as previously suggested for facilitation and sensitization (Michael et al., 1998; Lyons et al., 2006). We found that induction and maintenance of ITM was dependent upon MAPK. Because transcription is not required for ITM, the requirement for prolonged MAPK activation may function downstream to enhance protein synthesis.

For memory formation in vivo, one might speculate that compensatory mechanisms would allow decreased activity in one signaling pathway as long as significant activation of other pathways occurred. Our results suggest that is not the case, as in vivo inhibition of either MAPK, PKA or PKC blocked ITM formation and maintenance. Potentially, immediate activation of one cascade results in the induction or persistence of a second kinase cascade as previously observed for MAPK and PKC translocation. As PKA and PKC downstream signaling have been suggested to induce MAPK activation (for review, see Reissner et al., 2006), we tested the requirements for sustained MAPK activation and found that protein synthesis, but neither PKA nor PKC activity was required for the second phase of MAPK activity after training. Given that the prolonged phase of MAPK activity evident at $1 \mathrm{~h}$ is necessary for intermediate and long-term LFI memory, it is probable that both forms of memory use protein synthesis-dependent activation of MAPK. We previously determined that prolonged, but not immediate, MAPK activation was dependent in part upon PKG signaling (Michel et al., 2011b). Thus, there appear to be multiple upstream mechanisms required for sustained MAPK signaling.

The distinct requirements of intermediate-term LFI memory for persistent kinase activity in multiple pathways and for protein translation suggest that each of these kinase pathways plays a unique role in ITM compared with the functions in STM or LTM. Potentially, ITM requires an early phase of protein synthesis that is necessary for persistent PKA and MAPK activation. Later the persistent activation of all three kinase pathways may converge to upregulate local protein synthesis necessary for memory maintenance. In Aplysia, PKA and PKC activation have been shown necessary for the activation of TOR and inhibition of phosphatase activity, increased S6 kinase activity and downstream local protein synthesis (Khan et al., 2001). Studies of mammalian LTP and invertebrate memory support an upstream role for the MAPK cascade in protein translation via mTOR activation (Gelinas et al., 2007; Tsokas et al., 2007).

Our results combined with previous research provide insight into a global framework of molecular changes induced by training with discrete subsets of these changes required for STM, ITM, and LTM. Further delineation of the function and cellular location of immediate and persistent kinases in ITM undoubtedly will be the subject of future research. It remains possible that activation of these signaling cascades may occur in different neurons with separate kinase pathways activated in presynaptic and postsynaptic mechanisms. Through the use of a massed training paradigm that results in short-, intermediate-, and long-term 
memory, our results highlight the complexity of memory formation even in animals with relatively simple nervous systems.

\section{References}

Abel T, Nguyen PV (2008) Regulation of hippocampus-dependent memory by cyclic AMP-dependent protein kinase. Prog Brain Res 169:97-115.

Antonov I, Kandel ER, Hawkins RD (2010) Presynaptic and postsynaptic mechanisms of synaptic plasticity and metaplasticity during intermediate-term memory formation in Aplysia. J Neurosci 30:5781-5791.

Atkins CM, Selcher JC, Petraitis JJ, Trzaskos JM, Sweatt JD (1998) The MAPK cascade is required for mammalian associative learning. Nat Neurosci 1:602-609.

Bailey CH, Montarolo P, Chen M, Kandel ER, Schacher S (1992) Inhibitors of protein and RNA synthesis block structural changes that accompany long-term heterosynaptic plasticity in Aplysia. Neuron 9:749-758.

Bailey CH, Kaang BK, Chen M, Martin KC, Lim CS, Casadio A, Kandel ER (1997) Mutation in the phosphorylation sites of MAP kinase blocks learning-related internalization of apCAM in Aplysia sensory neurons. Neuron 18:913-924.

Bailey CH, Barco A, Hawkins RD, Kandel ER, Byrne JH (2008) Molecular studies of learning and memory in Aplysia and the hippocampus: a comparative analysis of implicit and explicit memory storage. In: Learning and memory: a comprehensive reference (Byrne JH, ed), pp 11-29. Oxford: Academic.

Baxter DA, Byrne JH (2006) Feeding behavior of Aplysia: a model system for comparing cellular mechanisms of classical and operant conditioning. Learn Mem 13:669-680.

Berry J, Krause WC, Davis RL (2008) Olfactory memory traces in Drosophila. Prog Brain Res 169:293-304.

Botzer D, Markovich S, Susswein AJ (1998) Multiple memory processes following training that a food is inedible in Aplysia. Learn Mem 5:204-219.

Bougie JK, Lim T, Farah CA, Manjunath V, Nagakura I, Ferraro GB, Sossin WS (2009) The atypical protein kinase C in Aplysia can form a protein kinase M by cleavage. J Neurochem 109:1129-1143.

Burrell BD, Sahley CL (2001) Learning in simple systems. Curr Opin Neurobiol 11:757-764.

Cai D, Pearce K, Chen S, Glanzman DL (2011) Protein kinase M maintains long-term sensitization and long-term facilitation in Aplysia. J Neurosci 31:6421-6431.

Casadio A, Martin KC, Giustetto M, Zhu H, Chen M, Bartsch D, Bailey CH, Kandel ER (1999) A transient, neuron-wide form of CREB-mediated long-term facilitation can be stabilized at specific synapses by local protein synthesis. Cell 99:221-237.

Castellucci VF, Frost WN, Goelet P, Montarolo PG, Schacher S, Morgan JA, Blumenfeld H, Kandel ER (1986) Cell and molecular analysis of longterm sensitization in Aplysia. J Physiol (Paris) 81:349-357.

Chwang WB, Arthur JS, Schumacher A, Sweatt JD (2007) The nuclear kinase mitogen- and stress-activated protein kinase 1 regulates hippocampal chromatin remodeling in memory formation. J Neurosci 27:12732-12742.

Cohen-Armon M, Visochek L, Katzoff A, Levitan D, Susswein AJ, Klein R, Valbrun M, Schwartz JH (2004) Long-term memory requires polyADPribosylation. Science 304:1820-1822.

Cropper EC, Evans CG, Hurwitz I, Jing J, Proekt A, Romero A, Rosen SC (2004) Feeding neural networks in the mollusc Aplysia. Neurosignals 13:70-86.

Crow T, Xue-Bian JJ, Siddiqi V (1999) Protein synthesis-dependent and mRNA synthesis-independent intermediate phase of memory in Hermissenda. J Neurophysiol 82:495-500.

Davies SP, Reddy H, Caivano M, Cohen P (2000) Specificity and mechanism of action of some commonly used protein kinase inhibitors. Biochem J 351:95-105.

Davis RL (2005) Olfactory memory formation in Drosophila: from molecular to systems neuroscience. Annu Rev Neurosci 28:275-302.

Elliott CJ, Susswein AJ (2002) Comparative neuroethology of feeding control in molluscs. J Exp Biol 205:877-896.

Emptage NJ, Mauelshagen J, Carew TJ (1996) Threshold serotonin concentration required to produce synaptic facilitation differs for depressed and nondepressed synapses in Aplysia sensory neurons. J Neurophysiol 75:843-854.

Farah CA, Weatherill D, Dunn TW, Sossin WS (2009) PKC differentially translocates during spaced and massed training in Aplysia. J Neurosci 29:10281-10286.

Frey S, Frey JU (2008) 'Synaptic tagging' and 'cross-tagging' and related associative reinforcement processes of functional plasticity as the cellular basis for memory formation. Prog Brain Res 169:117-143.

Fulton D, Kemenes I, Andrew RJ, Benjamin PR (2005) A single timewindow for protein synthesis-dependent long-term memory formation after one-trial appetitive conditioning. Eur J Neurosci 21:1347-1358.

Gelinas JN, Banko JL, Hou L, Sonenberg N, Weeber EJ, Klann E, Nguyen PV (2007) ERK and mTOR signaling couple beta-adrenergic receptors to translation initiation machinery to gate induction of protein synthesisdependent long-term potentiation. J Biol Chem 282:27527-27535.

Ghirardi M, Montarolo PG, Kandel ER (1995) A novel intermediate stage in the transition between short- and long-term facilitation in the sensory to motor neuron synapse of Aplysia. Neuron 14:413-420.

Gibbs ME, Ng KT (1976) Diphenylhydantoin facilitation of labile, proteinindependent memory. Brain Res Bull 1:203-208.

Grünbaum L, Müller U (1998) Induction of a specific olfactory memory leads to a long-lasting activation of protein kinase $\mathrm{C}$ in the antennal lobe of the honeybee. J Neurosci 18:4384-4392.

Houeland G, Nakhost A, Sossin WS, Castellucci VF (2007) PKC modulation of transmitter release by SNAP-25 at sensory-to-motor synapses in Aplysia. J Neurophysiol 97:134-143.

$\mathrm{Hu}$ JY, Wu F, Schacher S (2006) Two signaling pathways regulate the expression and secretion of a neuropeptide required for long-term facilitation in Aplysia. J Neurosci 26:1026-1035.

Johnston ANB, Burne THJ, Rose SPR (1998) Observation learning in dayold chicks using a one-trial passive avoidance learning paradigm. Anim Behav 56:1347-1353.

Kandel ER (2001) The molecular biology of memory storage: a dialogue between genes and synapses. Science 294:1030-1038.

Katzoff A, Ben-Gedalya T, Susswein AJ (2002) Nitric oxide is necessary for multiple memory processes after learning that a food is inedible in Aplysia. J Neurosci 22:9581-9594.

Katzoff A, Miller N, Susswein AJ (2010) Nitric oxide and histamine signal attempts to swallow: a component of learning that food is inedible in Aplysia. Learn Mem 17:839-851.

Kelleher RJ 3rd, Govindarajan A, Jung HY, Kang H, Tonegawa S (2004) Translational control by MAPK signaling in long-term synaptic plasticity and memory. Cell 116:467-479.

Khabour O, Levenson J, Lyons LC, Kategaya LS, Chin J, Byrne JH, Eskin A (2004) Coregulation of glutamate uptake and long-term sensitization in Aplysia. J Neurosci 24:8829-8837.

Khan A, Pepio AM, Sossin WS (2001) Serotonin activates S6 kinase in a rapamycin-sensitive manner in Aplysia synaptosomes. J Neurosci 21:382-391.

Kruger KE, Sossin WS, Sacktor TC, Bergold PJ, Beushausen S, Schwartz JH (1991) Cloning and characterization of $\mathrm{Ca}(2+)$-dependent and $\mathrm{Ca}(2+)$ independent PKCs expressed in Aplysia sensory cells. J Neurosci 11:2303-2313.

Levenson J, Byrne JH, Eskin A (1999) Levels of serotonin in the hemolymph of Aplysia are modulated by light/dark cycles and sensitization training. J Neurosci 19:8094-8103.

Levitan D, Lyons LC, Perelman A, Green CL, Motro B, Eskin A, Susswein AJ (2008) Training with inedible food in Aplysia causes expression of C/EBP in the buccal but not cerebral ganglion. Learn Mem 15:412-416.

Li Q, Roberts AC, Glanzman DL (2005) Synaptic facilitation and behavioral dishabituation in Aplysia: dependence on release of $\mathrm{Ca}^{2+}$ from postsynaptic intracellular stores, postsynaptic exocytosis, and modulation of postsynaptic AMPA receptor efficacy. J Neurosci 25:5623-5637.

Lorenzetti FD, Baxter DA, Byrne JH (2008) Molecular mechanisms underlying a cellular analog of operant reward learning. Neuron 59:815-828.

Lukowiak K, Adatia N, Krygier D, Syed N (2000) Operant conditioning in Lymnaea: evidence for intermediate- and long-term memory. Learn Mem $7: 140-150$.

Lyons LC, Rawashdeh O, Katzoff A, Susswein AJ, Eskin A (2005) Circadian modulation of complex learning in diurnal and nocturnal Aplysia. Proc Natl Acad Sci U S A 102:12589-12594.

Lyons LC, Collado MS, Khabour O, Green CL, Eskin A (2006) The circadian clock modulates core steps in long-term memory formation in Aplysia. J Neurosci 26:8662-8671. 
Lyons LC, Green CL, Eskin A (2008) Intermediate-term memory is modulated by the circadian clock. J Biol Rhythms 23:538-542.

MacDonald JF, Kotecha SA, Lu WY, Jackson MF (2001) Convergence of PKC-dependent kinase signal cascades on NMDA receptors. Curr Drug Targets 2:299-312.

Manseau F, Fan X, Hueftlein T, Sossin W, Castellucci VF (2001) $\mathrm{Ca}^{2+}$ independent protein kinase C Apl II mediates the serotonin-induced facilitation at depressed Aplysia sensorimotor synapses. J Neurosci 21:1247-1256.

Marinesco S, Carew TJ (2002) Serotonin release evoked by tail nerve stimulation in the CNS of Aplysia: characterization and relationship to heterosynaptic plasticity. J Neurosci 22:2299-2312.

Martin KC, Michael D, Rose JC, Barad M, Casadio A, Zhu H, Kandel ER (1997) MAP kinase translocates into the nucleus of the presynaptic cell and is required for long-term facilitation in Aplysia. Neuron 18:899-912.

Mauelshagen J, Parker GR, Carew TJ (1996) Dynamics of induction and expression of long-term synaptic facilitation in Aplysia. J Neurosci 16:7099-7108.

Mauelshagen J, Sherff CM, Carew TJ (1998) Differential induction of longterm synaptic facilitation by spaced and massed applications of serotonin at sensory neuron synapses of Aplysia californica. Learn Mem 5:246-256.

Michael D, Martin KC, Seger R, Ning MM, Baston R, Kandel ER (1998) Repeated pulses of serotonin required for long-term facilitation activate mitogen-activated protein kinase in sensory neurons of Aplysia. Proc Natl Acad Sci U S A 95:1864-1869.

Michel M, Green CL, Lyons LC (2011a) PKA and PKC are required for long-term but not short-term in vivo operant memory in Aplysia. Learn Mem 18:19-23.

Michel M, Green CL, Eskin A, Lyons LC (2011b) PKG-mediated MAPK signaling is necessary for long-term operant memory in Aplysia. Learn Mem 18:108-117.

Moressis A, Friedrich AR, Pavlopoulos E, Davis RL, Skoulakis EM (2009) A dual role for the adaptor protein DRK in Drosophila olfactory learning and memory. J Neurosci 29:2611-2625.

Müller U, Carew TJ (1998) Serotonin induces temporally and mechanistically distinct phases of persistent PKA activity in Aplysia sensory neurons. Neuron 21:1423-1434.

Osten P, Valsamis L, Harris A, Sacktor TC (1996) Protein synthesisdependent formation of protein kinase Mzeta in long-term potentiation. J Neurosci 16:2444-2451.

Pagani MR, Oishi K, Gelb BD, Zhong Y (2009) The phosphatase SHP2 regulates the spacing effect for long-term memory induction. Cell 139:186-198.

Patterson TA, Alvarado MC, Warner IT, Bennett EL, Rosenzweig MR (1986) Memory stages and brain asymmetry in chick learning. Behav Neurosci 100:856-865.

Purcell AL, Sharma SK, Bagnall MW, Sutton MA, Carew TJ (2003) Activation of a tyrosine kinase-MAPK cascade enhances the induction of longterm synaptic facilitation and long-term memory in Aplysia. Neuron 37:473-484.

Reissner KJ, Shobe JL, Carew TJ (2006) Molecular nodes in memory processing: insights from Aplysia. Cell Mol Life Sci 63:963-974.

Rosenegger D, Lukowiak K (2010) The participation of NMDA receptors, PKC, and MAPK in the formation of memory following operant conditioning in Lymnaea. Mol Brain 3:24.

Sacktor TC (2008) PKMzeta, LTP maintenance, and the dynamic molecular biology of memory storage. Prog Brain Res 169:27-40.

Sangha S, Scheibenstock A, McComb C, Lukowiak K (2003) Intermediate and long-term memories of associative learning are differentially affected by transcription versus translation blockers in Lymnaea. J Exp Biol 206:1605-1613.

Schwärzel M, Müller U (2006) Dynamic memory networks: dissecting molecular mechanisms underlying associative memory in the temporal domain. Cell Mol Life Sci 63:989-998.

Selcher JC, Atkins CM, Trzaskos JM, Paylor R, Sweatt JD (1999) A necessity for MAP kinase activation in mammalian spatial learning. Learn Mem 6:478-490.

Sharma SK, Carew TJ (2002) Inclusion of phosphatase inhibitors during Western blotting enhances signal detection with phospho-specific antibodies. Anal Biochem 307:187-189.
Sharma SK, Bagnall MW, Sutton MA, Carew TJ (2003a) Inhibition of calcineurin facilitates the induction of memory for sensitization in Aplysia: requirement of mitogen-activated protein kinase. Proc Natl Acad Sci U S A 100:4861-4866.

Sharma SK, Sherff CM, Shobe J, Bagnall MW, Sutton MA, Carew TJ (2003b) Differential role of mitogen-activated protein kinase in three distinct phases of memory for sensitization in Aplysia. J Neurosci 23:3899-3907.

Sherff CM, Carew TJ (2004) Parallel somatic and synaptic processing in the induction of intermediate-term and long-term synaptic facilitation in Aplysia. Proc Natl Acad Sci U S A 101:7463-7468.

Shobe JL, Sharma SK, Carew TJ (2005) Long-term memory for sensitization in Aplysia requires sustained ERK activity. Soc Neurosci Abstr 31:540.10.

Shobe JL, Zhao Y, Stough S, Ye X, Hsuan V, Martin KC, Carew TJ (2009) Temporal phases of activity-dependent plasticity and memory are mediated by compartmentalized routing of MAPK signaling in Aplysia sensory neurons. Neuron 61:113-125.

Sindreu CB, Scheiner ZS, Storm DR (2007) $\mathrm{Ca}^{2+}$-stimulated adenylyl cyclases regulate ERK-dependent activation of MSK1 during fear conditioning. Neuron 53:79-89.

Sossin WS (2007) Isoform specificity of protein kinase Cs in synaptic plasticity. Learn Mem 14:236-246.

Stough S, Shobe JL, Carew TJ (2006) Intermediate-term processes in memory formation. Curr Opin Neurobiol 16:672-678.

Susswein AJ, Schwarz M, Feldman E (1986) Learned changes of feeding behavior in Aplysia in response to edible and inedible foods. J Neurosci 6:1513-1527.

Sutton MA, Carew TJ (2000) Parallel molecular pathways mediate expression of distinct forms of intermediate-term facilitation at tail sensorymotor synapses in Aplysia. Neuron 26:219-231.

Sutton MA, Masters SE, Bagnall MW, Carew TJ (2001) Molecular mechanisms underlying a unique intermediate phase of memory in Aplysia. Neuron 31:143-154.

Sutton MA, Bagnall MW, Sharma SK, Shobe J, Carew TJ (2004) Intermediate-term memory for site-specific sensitization in Aplysia is maintained by persistent activation of protein kinase C. J Neurosci 24:3600-3609.

Sweatt JD (2010) Mechanisms of memory, Ed 2. Amsterdam: Academic.

Taglialatela G, Hogan D, Zhang WR, Dineley KT (2009) Intermediate- and long-term recognition memory deficits in $\mathrm{Tg} 2576$ mice are reversed with acute calcineurin inhibition. Behav Brain Res 200:95-99.

Tsokas P, Ma T, Iyengar R, Landau EM, Blitzer RD (2007) Mitogenactivated protein kinase upregulates the dendritic translation machinery in long-term potentiation by controlling the mammalian target of rapamycin pathway. J Neurosci 27:5885-5894.

Udo H, Jin I, Kim JH, Li HL, Youn T, Hawkins RD, Kandel ER, Bailey CH (2005) Serotonin-induced regulation of the actin network for learningrelated synaptic growth requires Cdc42, N-WASP, and PAK in Aplysia sensory neurons. Neuron 45:887-901.

Villareal G, Li Q, Cai D, Glanzman DL (2007) The role of rapid, local, postsynaptic protein synthesis in learning-related synaptic facilitation in Aplysia. Curr Biol 17:2073-2080.

Villareal G, Li Q, Cai D, Fink AE, Lim T, Bougie JK, Sossin WS, Glanzman DL (2009) Role of protein kinase C in the induction and maintenance of serotonin-dependent enhancement of the glutamate response in isolated siphon motor neurons of Aplysia californica. J Neurosci 29:5100-5107.

Weeber EJ, Atkins CM, Selcher JC, Varga AW, Mirnikjoo B, Paylor R, Leitges $\mathrm{M}$, Sweatt JD (2000) A role for the beta isoform of protein kinase C in fear conditioning. J Neurosci 20:5906-5914.

Weragoda RM, Ferrer E, Walters ET (2004) Memory-like alterations in Aplysia axons after nerve injury or localized depolarization. J Neurosci 24:10393-10401.

Yanow SK, Manseau F, Hislop J, Castellucci VF, Sossin WS (1998) Biochemical pathways by which serotonin regulates translation in the nervous system of Aplysia. J Neurochem 70:572-583.

Zhao Y, Leal K, Abi-Farah C, Martin KC, Sossin WS, Klein M (2006) Isoform specificity of PKC translocation in living Aplysia sensory neurons and a role for $\mathrm{Ca}^{2+}$-dependent PKC APL I in the induction of intermediate-term facilitation. J Neurosci 26:8847-8856. 